\title{
FORMATION OF BRAND POSITIONING STRATEGY
}

\author{
Diana Fayvishenko' \\ Kyiv National University of Trade and Economics, Ukraine
}

\begin{abstract}
The purpose of this article is defining the term of positioning, as well as creation and implementation of the success principles of the brand positioning strategies, discussed the process of creating a positional scheme. Methodology. Applied the principle of systems, comparative analysis, induction, deductive method and gnoseological analysis (analytical, synthesis, logical, comparison). Results from researching the principles of successful strategies for the development and positioning of a brand brought to the following conclusions: the brand positioning is a process of creating its own image, distinctive properties, positive associations and values in consumers' mind in order to create a sustainable trademark image and ensure consumers' attachment to this trademark. Development and implementation of the company strategy of positioning comprises nine basic stages: 1) analysis of the external and internal environment, goods analysis; 2) trademark design; 3) selection and reasoning of differential positioning features; 4) defining a strategy (positioning method description); 5) defining strategic and tactical targets, foresight for their achievement; 6) development of an implementation strategy plan; 7) strategy implementation; 8) the results evaluation and strategy implementation control; 9) corrective actions. Prospects for further research. More detailed analysis of the positioning concepts, the rationale for a systematic approach to positioning, their use in practice. Background. Marketing positioning presents an opportunity for the promotion of trademarks, market share expansion, sales increase. Value/originality. A positioning strategy is the paramount part of the general positioning concept. The brand success on the market depends largely on the quality of development and realization of the positioning strategy. Therefore, this issue is a key to developing an efficient positioning system. The rationale of the chosen subject has no contradictions because the brand positioning should be addressed not only as a marketing issue but an important general economic and even a social task for the company, the solution of which contributes to the goal of improving the quality of life for all its employees.
\end{abstract}

Key words: brand, positioning, trademark, strategy of positioning, marketing.

JEL Classification: M00, M10

\section{Introduction}

Positioning is the most important stage in the asset management strategy of the trademark. Carefully considered positions provide development directions for the new products, market expansion, communication, pricing, selection of distribution channels. The brand positioning is a process of creating its own image, distinctive properties, positive associations and values in consumers' mind in order to create a sustainable trademark image and ensure consumers' attachment to this trademark (Fayvichenko, 2016). Today, based on the generalization (Stone, 1998, Davis, 2001, Trout, 2003), one can make a determination that brand positioning, as a process, begins with the design of a trademark position or, as is often seen in the literature, the concept of positioning. It is difficult to specify the essence of positioning when its ultimate goal is not clearly understood. To form a complete idea of the essence of positioning, it is important to determine what the ideal position of the trademark is. A clear representation of the ideal position of a trademark is a prerequisite for researching positioning as a target process and developing a system for evaluating its effectiveness.

\section{Principles of successful brand positioning}

In the aspect of the development of the rapid positioning of the brand, an attention is drawn to scientific developments by Kendukhov (2008) who believes that the problem is due to the lack of a clear understanding of what should be the ideal position of the trademark. A clear representation of the ideal position of a trademark is a prerequisite for researching positioning as a target process and developing a system for evaluating its effectiveness. Logically, the investigator proves that the initial premise in determining the ideal 
position of a trademark should serve the understanding of the ideal consumer (Aaker, Shansby, 1982). That is, the ideal position of the trademark: the perception of the trademark by the consumer, which forms the ideal consumer.

The ideal position should be reduced to absolute, only then can the criterion basis for assessing the effectiveness of positioning as a level of approximation to the ideal be determined.

Based on this premise, Kendukhov (2008) formulates the definition of the ideal position of the trademark this is its perception by the consumer, in which he is absolutely sure of the unique advantages of the trademark over other brands, with this brand associated exclusively with positive associations, it is perceived as irreplaceable value and necessary attribute of life; the perception in which the consumer is a fanatical supporter of this brand is fully convinced that consumers who buy goods under other brands make the wrong choice, considers it their duty to recommend this brand to other consumers, and feels the spiritual unity with consumers who have chosen this brand.

Thereby, the positioning of (Kendukhov, 2008) is a process of managing the perception of a trademark by a consumer whose purpose is: persuasion of the consumer in the unique advantages of this trademark over other brands; formation of the consumer's exclusive affiliates with this trademark; formation of the consumer's sense of the indispensability and vital necessity of the brand; formation of fanatical devotion to the brand; raising a sense of duty to recommend this brand to other consumers; forming a sense of spiritual unity with consumers who chose this brand; forming a belief in the consumer that other consumers who buy goods under other brands make the wrong choice.

The key to developing brand positioning and ensuring the successful outcome is an adherence to certain principles. The brand positioning should be performed under scientific methods, process-based and systematic approaches. The understanding and performing the management decisions in this area not only shall be based on the knowledge of marketing theory and practice but also on psychology, sociology, and other sciences.

The positioning is effective if it is done consistently and continuously. If in the absence of planning in the process of positioning elements will prevail chance, important aspects may be lost. Success, if achieved, must be consolidated and developed not through the weakening, but strengthening the effect on consumer's mind. Implementation of the trademark positioning must be performed under the rules of fair competition and strict compliance with the legislation on protection of trademarks (Trout, 2003).

A unique differentiating idea is a key to an effective brand positioning. Widely engage the company employees, existing and potential customers to work on the development of basic positioning systems. In addition to new ideas, such engagement has a positive effect on increasing the degree of attachment to the brand.

\section{Stages of development and introduction of brand positioning}

Note that today neither the scientific literature nor marketing practice has a justification for the development of brand positioning. Positioning, as a process, begins with the design of a trademark position or, as is often seen in the literature, the concept of positioning. Crevens (2003) sees the concept of positioning as a formulation of the essence of the company's offer, indicating the ability of the organization to meet the needs and preferences of consumers. The author quite rightly notes that the concept of positioning the company should be based on the reasons why customers prefer to deal with it, and not with its competitors, and to broadcast these reasons to the target audience. Extending the concept of positioning in marketing, J. Trout and S. Rivkin in "Differentiate or Die!" (2003) distinguish the following positioning tools: the championship in the category as a good differential idea; leadership as the most attractive and exciting idea; "Hot commodity" as a good, differential idea; differential idea of specialization; the latest development as a differential idea; the advantage is a differential idea; commodity as a good differential idea; possession of the attribute as a way of differentiation. Analysis of core studies on the subject (Keller, 2007, Mogileva 2010, Stone 1998) allows for picturing a generalized for development and implementation of the brand positioning that conditionally includes nine stages. The first stage implies a collection, processing, and analysis of the competitive environment data, competitors' policy regarding their own trademarks, the influence of macro-environment factors, analysis of the company market capabilities, its strengths and weaknesses, analysis of goods being sold or to be sold under this trademark. A trademark model is developed at the second stage: its image, the target audience is being determined, attributes, selection of the brand strategy (monobrand for monomarket, monobrand for polymarket, polybrand for polymarket) (Kendukhov, 2008). Selection of and rationale for differentiating positioning features are taking place at the third stage. The positioning strategy development based on the selected differentiating features takes place at the fourth stage. Strategic (perspective) and tactical (upcoming) positioning goals are developed via foresight of the strategy implementation results at the fifth stage. They must comply with each other. Typically, the second follows from the first. Each goal must be achievable in practice. Strategy implementation plan is developed at the sixth stage. Decisions on the methods and means to achieve goals are being taken, as well as the planning 
documents, plans and instructions are being brought to the performers. Each item of the plan must be drafted so that it is clear what kind of goal you achieve; what actions, measures, and works are to be made and to what deadline; who provides the resources, necessary to implement the decisions; what departments or persons are responsible for implementing the decision; who controls the implementation. Items of the plans must be rationalized, exposed clearly and correctly (contain a statement of action, parameters, etc., rather than calls to do something), easy for the performers to understand and connected with the general marketing plans of the company. It should be noted that at the stages 2-6 foresight has an extremely vital role - a scientifically proven foresight of the most plausible scenario for the trademark progress, alternative ways and plan implementation deadlines. It is based on identification and correct assessment of the market development trends, competitors' trademarks, changes in consumers' behaviour, and so on. Understanding the firm relations between different elements of the general positioning system, relations between the past, the present, and the future condition of the anticipated object. Not only the foresight rationalizes the development of the present trademark and the process of its positioning, but the trademarks anticipated to penetrate the market as well.

Scientific analysis and calculation are not the only things determining the foresight success. It is also determined by imagination and the ability to foresee, which depends on the experience of corresponding specialists. In practice, foresight uses three complementary development tools for foresight development.

Obtaining an image of the future development of the anticipated object based on the experience acquired during the analysis of similar objects that had taken place earlier. Extrapolation or interpolation, i.e. conditional prolongation of trends in the future, development patterns of which are well-known in the present and from the past. Modelling, i.e. building different models of the future condition, carried out in accordance with the expected or desired alterations of certain conditions, development perspectives of which are studied sufficiently. At the strategy implementation's seventh stage, plans are brought to the performers, specific actions and measures are carried out.

(Borgesi, Signori, Russo, 2005) reveals the strategic aspects of positioning in simple and double positioning. Under a simple positioning, researchers understand the element of marketing strategies associated with segmentation. In their view, this term should be considered as a part of consumer behaviour of the consumer, namely, as a part of the process of buying/ selling. This behaviour is divided into several stages. One of them is the "assessment of alternatives". It is at this stage that the consumer will weigh the information received about the product he intends to purchase.
The information is "undergoing the purification process" during the manufacturer's communication in order to create a specific, necessary for the consumer, vision of the product and its individual components, as well as a different view of the services in all possible variations.

These elements, which will thus be obtained, will compare consumers with their vision of an ideal product and thus streamline demand. Based on this, the consumer goes further in choosing a product. Regarding double positioning, the authors propose the following provisions that are relevant to the behaviour that entrepreneurs and managers dealing with dual positioning strategies should have: positioning based on the "adviser" should be based on the benefits that can grow. Such advantages may have a "technical" nature, for example - the simplicity of installing a complex product or the availability of spare parts, or direct advantages such as discounts and bonuses; the method, which informs the dual positioning to the consumer, should be such that as much as possible avoids confusion of the consumer. More precisely, the means, by which contact with the "advisor" is established, should be different from that used to establish contact with the immediate consumer.

This seems quite natural if one takes into account the fact that the number of people involved in the process is always different; the proliferation of international trade processes such as consumer and consumer management (CRM) makes it extremely easy to understand the nature of each individual consumer, and hence the people who are affected. It is possible even to distinguish the latter separately. This scenario makes the dual positioning strategies more effective. At the eighth stage, the results are evaluated and the strategy progress is monitored. Here, the comparison of actual efficiency indicators of the strategies' implementation with specific milestones that characterize the established strategic and tactical objectives. These guidelines should be clearly defined, rationalized and convey the final results. Control must not be narrowed down to a formal registration of deviations of the actual results from the planned ones. If actual results are not up to the planned results, it is required to analyse the whole chain of the cause and effect relations, identify the causes, conditions of their occurrence.

Control must be substantive, specific. Its objectives, parameters, and measures to be checked should be understood clearly. Monitoring of the implementation of plans and specific measures must be performed from the moment of their approval. During the monitoring, it is required to ensure the verification consistency of the corrective measure status, prevention of shortfalls, accumulation of positive experience. Monitoring must be done in a timely manner so that it is possible to correct the situation and take preventive measures. At the ninth stage, one must take, if necessary, corrective 
measures for the implementation of those stages, where the causes of actual results deviating from the planned results occurred.

The linking chain of all stages is the process of specialists' decision-making, who are responsible for development and implementation of the strategy. Approval of a decision always precedes the action, regardless of who performs the action - a decisionmaker or any other person. Each solution must include answers to the questions: what, when, and how to be done, who does.

\section{Conclusions}

Results from researching the principles of positioning strategies in marketing bring to the following conclusions: the trademark positioning is a process of creating its own image, distinctive properties, positive associations and values in consumers' mind in order to create a sustainable trademark image and ensure consumers' attachment to this trademark; the basis for any positioning concept is an idea of differentiation a trademark, goods according to some properties; decision making is a multi-staged process, which generally includes the following stages: determining the goal, for the achievement of which the decision is taken; collection and update of the output informational materials; specification of possible limitations (on the market, resources, potential consumer, etc.); development of possible scenarios; selecting a criteria for the evaluation of the decision's rectitude and efficiency; comparison and evaluation of each scenario under the adopted criteria; selection of the best option; foresight of the consequences occurred from implementation of the decision made; adjustment of the decision taken due to the foresight results or choosing another scenario if the prediction implies serious risks or inefficiencies of the decisions made due to the assumptions adopted during the foresight; foresight of the second scenario results and its adjustment or selection of the third scenario.

Prospects for further research: a more detailed analysis of the positioning concepts, analytical forecasts, the rationale for a systematic approach to positioning, their use in practice.

\section{References:}

Aaker D., Shansby J. (1982) Positioning your product. Business Horizons, no. May-June, pp. 56-62.

Balmer. J., Greyser S. (2003) Perspectives on Identity, Image, Reputation, Corporate Branding, and CorporateLevel Marketing. Revealing the Corporation, New York : Routledge, 363 p. (in English)

Borgesi A. (2005) The Possibility of Strategic Double Positioning. Marketing in Ukraine, no. 6, pp. 66-69.

Brand Valuation: The nancial value of brands. Retrieved from: http://www.brandchannel.com/

Davis S. (2001) Upravlenie aktivami torgovoj marki [Management of brand assets]. St. Peterburg: Peter, 272 p. (in Russian)

Crevens D. (2003) Strategicheskiy marketing [6-e izd] per. s angl. SPb.: Peter, 752 p. (in Russian).

Fayvichenko D. (2016) The concept of brand positioning. Mignarodnii naukovo-praktuchniy gurnal «Tovaru i runki $\gg$, no. 1(21), pp. 25-32 (in Ukrainian)

Keller K. (2007) Strategicheskij brand management: sozdanie, ocenka, upravlenie marochnim capitalom [Strategic brand management: creation, valuation, management of brand equity]. Moscow: Publishing house "Williams", 704 p. (in Russian)

Kendyuhov V. (2008) Effectivnist vucorustannya marochnogo capital [Effectiveness of using branded capital]. Donetsk: Institute economy promislovist, pp. 96-103 (in Ukrainian)

Mogileva A. (2010) Zmist ta osobluvosti posizionuvannya tovariv na rinku [The content and features of the positioning of goods on the market]. Odessa: TSEDR, $273 \mathrm{p}$. (in Ukrainian)

Smith D., Park C. (1992). The effects of brand extensions are market share and advertising efficiency. Journal of Marketing Research, vol. 29 (3), pp. 296-313.

Stone M. (1998) Prjamoe popadanie: factoru prjamogo marketinga [Direct hit: direct marketing factors]. Minsk: Amalfeya, 448 p. (in Russian)

Tompson A. (1998) Stratehycheskyi menedzhment. Yskusstvo razrabotky y realyzatsyy stratehyy [Strategic management. The art of strategy development and implementation]. Moscow : Banky y byrzhy, YuNYTY, 578 p. (in Russian)

Trout J. (2003) Differentiate or die! Survival in an era of fatal competition. St. Petersburg: Peter, 224 p.

Trout J. (2003) Positioning. Battle for recognizability. St. Petersburg: Peter, 256 p.

Wind J. Y. (1982) Product Policy: Concepts, Methods and Strategy. Reading, MA: Addison-Wesley, 505 p. 